\title{
Research on Construction Action-Oriented Curriculum System in Military Vocational Education
}

\author{
Yanming Yang*, Wanchun Gao and Haiyan Zheng \\ Naval Aeronautical and Astronautical University Qingdao Campus; Qingdao 266041; China \\ *yymqd@126.com
}

Keywords: Curriculum System, Action-Oriented, Military Vocational Education.

\begin{abstract}
On the basis of research results of action-oriented curriculum system abroad and combining with the actual situation of military academies, this paper puts forward a new idea to construct the action-oriented curriculum system of military vocational education, and explores a "Six-step" reverse construction mode of the action-oriented curriculum system. At last, the paper gives "Five Integration" implementation measures of the action-oriented curriculum system.
\end{abstract}

\section{Introduction}

The core of teaching reform is the reform of teaching content. As the important carrier of teaching contents, curriculum status is very important. The construction of curriculum system is the top-level design of curriculum reform. Therefore, curriculum system construction is the most important teaching reform. The construction of the curriculum system is a systematic project. This article comprehensively carries out the instruction spirit of "Focusing on the actual combat and moving closer to the troops", mainly aiming at the deep research and exploration of the construction of the current cadre post education curriculum system. This paper proposes a strategy for the construction of action-oriented curriculum system for the development of post competency.

\section{Theoretical Basis and Construction Ideas of Action-Oriented Curriculum System}

Theoretical Basis. Action-oriented education theory is a kind of modern educational theory in the 1980s. It is "learning by doing", and the action-oriented teaching model has been applied in vocational education in many countries. Action-oriented teaching model "is not a specific teaching method, but a guide to organize the entire teaching process, including an action-oriented curriculum system, action-oriented teaching content, action-oriented assessment standards, Action-oriented teaching organizations and action-oriented teaching methods."

In the curriculum system construction draw lessons from action-oriented theory, will further highlight the vocational education "teaching, learning, doing" integration features. Therefore, it is a hot topic to study the application of action-oriented theory in the construction of curriculum system and to construct the curriculum system with the characteristics of military vocational education, which has become a hot topic in the teaching reform of military academies.

Construction Ideas. The curriculum system of action-oriented course is designed through three stages of curriculum development, and develops three-level ladder course. Each course is supported by three carriers, and through dual cooperation in the course of implementation, the military vocational ability is improved. The construction ideas are shown in Figure 1.

Three stages of curriculum development. Occupation demand analysis stage: to solve the problem of accurate positioning of professional training mode; determine the stage: the training mode of personnel training as the core of the occupation ability; curriculum development stage: to solve the basis for curriculum, curriculum carrier selection, curriculum content, reconstruction of curriculum standards, curriculum situation establishment, curriculum implementation and evaluation etc..

Three levels of courses. Three levels of the ladder course refers to the development of courses, follow the formation of professional ability of the law, the curriculum around the key ability to develop from easy to difficult to the job should have the key ability to develop three levels of 
action-oriented curriculum in order to achieve curriculum Structure and service ability of the unity of training, fully embodies the ability-based, action-oriented core concept.

Three carriers. The first carrier is the construction of the field of action (typical task); the second carrier is the construction of the learning domain (teaching project); the third carrier is the construction of the learning situation (teaching unit).

Dual cooperation. Dual cooperation refers to the cooperation between the institutions and the troops to accomplish the teaching task. Including the establishment of dual cooperation in practice teaching content and practice teaching platform, dual teacher team, dual assessment and evaluation system construction and so on.

One goal. One goal is to achieve the upgrading of military professional capacity, training students the ability to sustainable development to adapt to the rapid development of military equipment and combat needs.

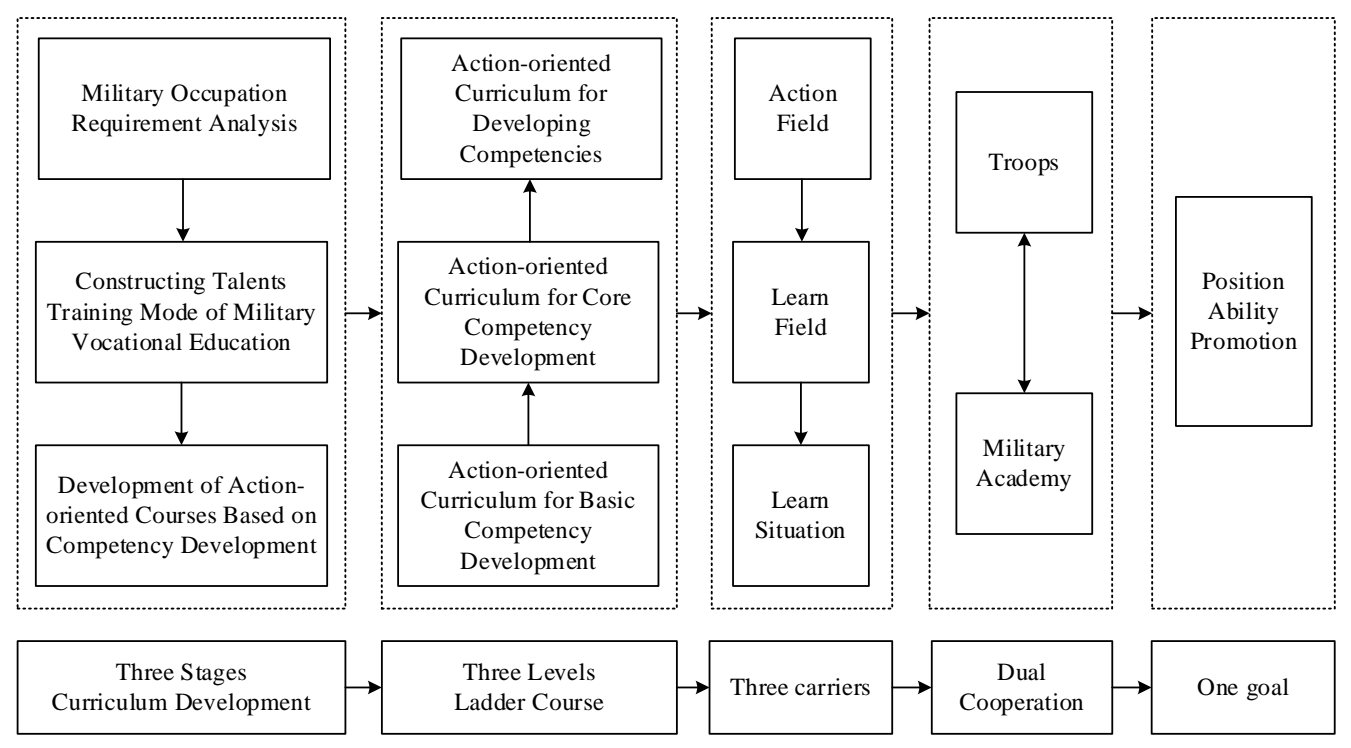

Fig. 1 Design framework of action-oriented curriculum system in military vocational education

\section{Construction Method of Action Oriented Curriculum System}

Establishing the Reverse Construction Strategy of Action-oriented Curriculum System. Based on the international advanced action-oriented vocational education theory and the characteristics of military vocational education, this paper puts forward the reverse construction strategy of action oriented curriculum system. The reverse construction strategy of the curriculum system is to take the demand of the army as the guidance, and reverse the derivation and analysis of the formation of professional ability. It includes the following aspects: (1) Constructing the talent cultivation mode with the core of military professional ability training. (2) The development of three-level action-oriented ladder courses. (3) Action-oriented curriculum of the three-carrier design, the formation of teaching content based on the work process. (4) Dual cooperation mechanism construction, the formation of action-oriented curriculum support system.

Constructing an Action-oriented Curriculum System for Aviation Equipment Quality Management. In practice, the practice of aviation equipment quality management is explored. Based on the principle of "curriculum system and job requirement adaptation, curriculum standards and vocational skills, course content and job assignment", based on the work content of post, combined with the actual work of aviation equipment quality management, build action-oriented curriculum system. The construction of action-oriented curriculum system is carried out according to the train of thought of "training object - position system - training system - curriculum system - knowledge module - curriculum". 
The Main Measures of Implementing Action-Oriented Curriculum System. In order to ensure the effective implementation of the curriculum system, the main measures taken: (1) To develop "four docking" the basic principles. That is, professional training objectives and the needs of the troops docking, curriculum standards and vocational skills docking, course content and job tasks docking, teaching process and post work process docking. (2) The use of "job-oriented, task-driven" approach to select teaching content. (3) Explore the integration of teaching methods. (4) Set up a wide range of evaluation assessment system. (5) Construction of "classroom + laboratory + field + troops" four in one teaching environment.

\section{Practical Innovation of Action-Oriented Curriculum System}

Put Forward Action-Oriented Curriculum Design New Ideas in the Military Vocational Education. The paper puts forward the design idea of action-oriented curriculum system (as shown in Fig. 2). The advanced design idea of the course is undoubtedly a new construction of military vocational education curriculum system, which is based on the action-oriented theory of modern higher vocational education and the characteristics of military vocational education.

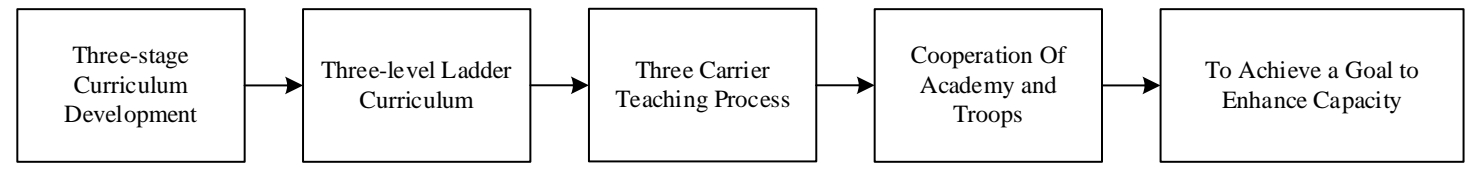

Fig. 2 Design process of action-oriented curriculum system

Exploring a Construction Mode of "Six-step" Action-Oriented Curriculum System in Military Vocational Education. According to the design idea of action-oriented curriculum system, this paper explores the "Six-step" reverse construction mode of curriculum system from design to implementation (as shown in Fig. 3). The construction method is undoubtedly a new model for the construction of military vocational education curriculum system.

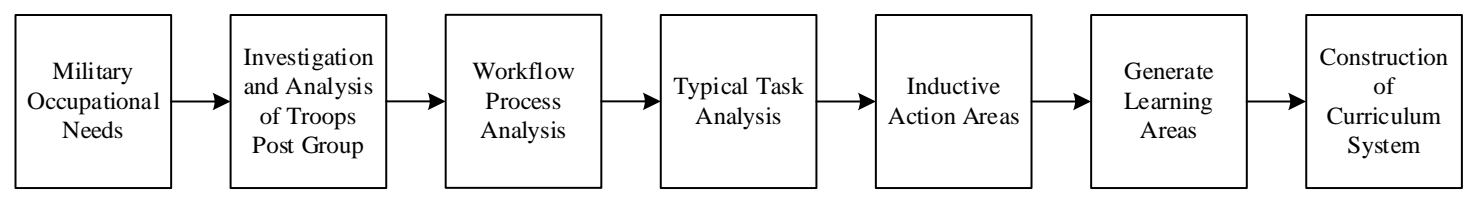

Fig. 3 Construction process of "Six-step" action oriented curriculum system

Probe into the Implementation of the "Five Integration" Action-Oriented Curriculum System. In order to adapt to the needs of the military vocational education reform to deepen the reform, based on the reform of teaching, learning and doing, the paper explores the supporting measures of "five integration" action-oriented curriculum system (as shown in Fig. 4).

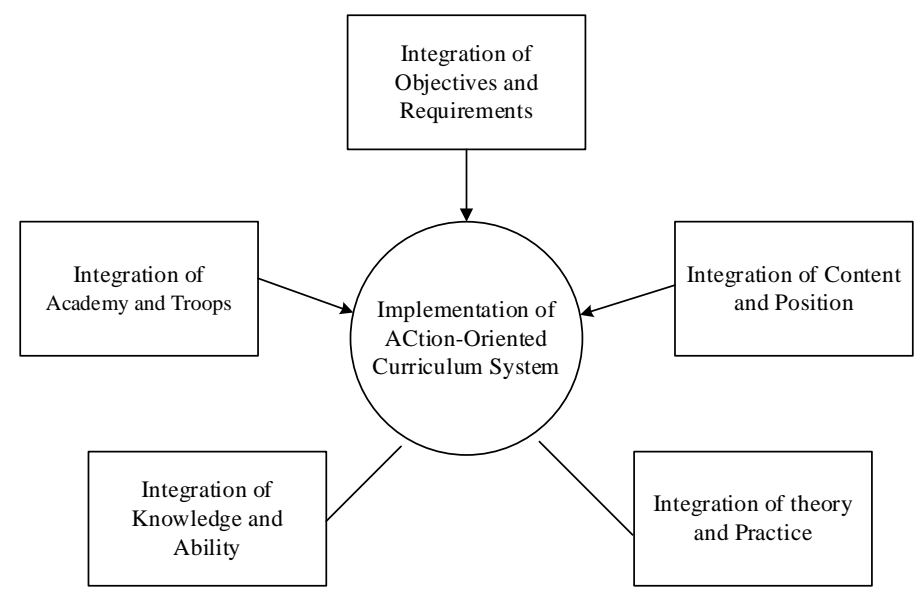

Fig. 4 Implementing measures of "five integrated" action-oriented curriculum 


\section{Conclusions}

Through the construction of action-oriented curriculum system, it solves the teaching problems of the following two aspects: First, it solves the top-level design problem of the teaching content reform in military vocational education. The construction of the curriculum system is the core content of the reform of the teaching content. This paper puts forward the reversible construction method of the action-oriented curriculum system with strong practicability, and gives the concrete practice case with the aviation equipment quality management specialty. Second, it solves the military vocational education curriculum system and teaching practice organic integration problem. In the process of teaching reform, it is easy for the top-level design and the end practice to be out of line. This paper not only solves the problem of how to construct the curriculum system, but also solves the problem of how to use and how to evaluate. On the basis of constructing action-oriented curriculum system, the corresponding measures are given to the concrete implementation of the curriculum system.

\section{References}

[1] Richards, K. Andrew R., and J. D. Ressler. Engaging Preservice Teachers in Context-based, Action-oriented Curriculum Development. Journal of Physical Education Recreation \& Dance 87.3(2016):36-43.

[2] MLAFa-Hong, L. I. Discussion on Concepts and Ideas of the Work Process-oriented Curriculum Design for Turf Establishment and Ground Cover Plants Cultivation. Journal of Anhui Agricultural Sciences (2012).

[3] Xing, Meifeng, C. T. Department, and B. V. Amp. Consideration on the Thoughts of Action Ability and Action-oriented Teaching in German. Journal of Baotou Vocational \& Technical College (2014).

[4] LIU Song-lin, XIE Li-min. Vocational and Technical Education. Vol. 30 (2009), p.12-17.

[5] Ding, Hai. The Study of the Action-oriented Education Mold in the Molde Design and Manufacture. Journal of Henan Mechanical \& Electrical Engineering College (2010).

[6] Liu, Lihong. Research on Action-Oriented Teaching Organizing Based on Germany Vocational Education. Journal of Beijing Polytechnic College (2009).

[7] Xiao, G. U., and J. J. Pang. Action-oriented curriculum establishment of "integrated practiceon road engineering”. China Construction Education (2009). 